\title{
Rabbinic Parodies of Jewish and Christian Literature
}

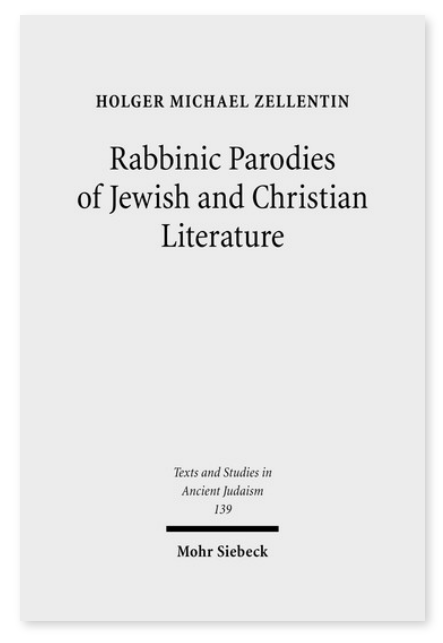

2011. IX, 275 Seiten. TSAJ 139

ISBN 978-3-16-151472-2

DOI 10.1628/978-3-16-151472-2

eBook PDF 129,00€

ISBN 978-3-16-150647-5

Leinen $129,00 €$
[Rabbinische Parodien der jüdischen und christlichen Literatur.]

Veröffentlicht auf Englisch.

Gibt es Parodien in Talmud und Midrasch? Holger M. Zellentin untersucht, wie die Rabbis der Spätantike bestehende Texte imitieren, um komische Unterschiede zwischen Original und Parodie zu betonen. Das Ergebnis zeigt, wie selbstsicher die rabbinische Gesellschaft und ihre Literatur an den grossen Debatten des byzantinischen und des sassanidischen Reiches teilnehmen. Die rabbinischen Parodien kommentieren Themen wie Pädagogik, Alkoholabstinenz, Traumdeutung, Erbrecht, rituelle Reinheit und christlichen Triumphalismus und Askese. Die Rabbis, in intimer Konversation mit der Hebräischen Bibel, erweisen sich als kritische Neuerfinder der jüdischen Tradition und als spielerische Kommentatoren von Evangelienpassagen, die für ihre christlichen Gesprächspartner von zentraler Bedeutung waren.

Holger Michael Zellentin Born 1976; 2007 PhD Princeton University; has taught at Rutgers University, the Graduate Theological Union, Berkeley, and at the University of California, Berkeley; teaches Jewish Studies at the University of Nottingham; 2012 Early Career Fellowship of the Arts and Humanities Research Council (UK).

Jetzt bestellen:

https://mohrsiebeck.com/buch/rabbinic-parodies-of-jewish-and-christian-literature-9783161514722?no_cache=1

order@mohrsiebeck.com

Telefon: $+49(0) 7071-923-17$

Telefax: +49 (0)7071-51104 